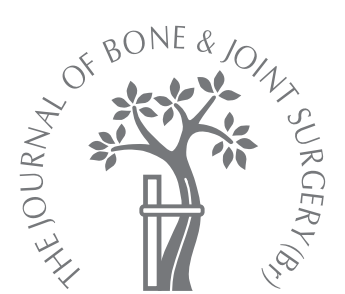

H. Aono,

T. Ohwada,

N. Kaneko,

T. Fuji,

M. Iwasaki

From Osaka

National Hospital,

Osaka, Japan

\title{
The post-operative changes in the level of inflammatory markers after posterior lumbar interbody fusion
}

\begin{abstract}
Inflammatory markers such as the C-reactive protein (CRP), white blood cell count and body temperature are easy to measure and are used as indicators of infection. The way in which they change in the early post-operative period after instrumented spinal surgery has not been reported in any depth.

We measured these markers pre-operatively and at one, four, seven and 14 days postoperatively in 143 patients who had undergone an instrumented posterior lumbar interbody fusion.

The CRP proved to be the only sensitive marker and had returned to its normal level in $48 \%$ of patients after 14 days. The CRP on day 7 was never higher than that on day 4 . Age, gender, body temperature, operating time and blood loss were not related to the CRP level. A high CRP does not in itself suggest infection, but any increase after four days may presage infection.
\end{abstract}

\begin{abstract}
H. Aono, MD, Orthopaedic
Surgeon

Department of Orthopaedic

Surgery

Osaka National Hospital, 2-1-14 Hoenzaka Chuo-ku, Osaka City, Osaka 540-0006, Japan.

- T. Ohwada, MD, Orthopaedic Surgeon

Department of Orthopaedic

Surgery

Kansai Rosai Hospital, 3-1-69

Inabaso Amagasaki City, Hyogo

660-8511, Japan.

N. Kaneko, MD, Orthopaedic Surgeon

- T. Fuji, MD, Orthopaedic

Surgeon

Department of Orthopaedic

Surgery

Osaka Koseinenkin Hospital, 4-

2-78Fukushima, Fukushima-ku,

Osaka City, Osaka 553-0003,

Japan.

M. Iwasaki, MD, Orthopaedic Surgeon

Department of Orthopaedic

Despite advances in prophylaxis, the incidence of deep infection after instrumented spinal surgery remains between $0.4 \%$ and $4.3 \%{ }^{1-4}$ and may be higher in patients undergoing fusion after spinal trauma. ${ }^{5}$ This can cause a significant problem if not addressed promptly, not least because of the proximity of the dura and its contents. ${ }^{3}$ Early detection of an infection may prevent substantial problems later. Although inflammatory markers such as the Creactive protein (CRP), white blood cell count (WBC) and body temperature can easily be measured, the way in which they change in the early post-operative period after instrumented spinal surgery has not been reported in depth. The aim of this study was to investigate how the level of these markers changes after an uncomplicated posterior lumbar interbody fusion.
\end{abstract}

Surgery

Osaka University Graduate

School of Medicine, 2-15

Yamadaoka Suita City, Osaka

565-0871, Japan.

Correspondence should be sent to $\mathrm{Dr} \mathrm{H}$. Aono; e-mail:

h-aono@umin.ac.jp

(C)2007 British Editorial Society of Bone and Joint Surgery doi:10.1302/0301-620X.89B11. $19478 \$ 2.00$

$J$ Bone Joint Surg $[\mathrm{Br}]$ 2007;89-B:1478-81.

Received 22 March 2007,

Accepted after revision 31 July

2007

\section{Patients and Methods}

Between January 2003 and April 2005, 168 consecutive patients underwent a posterior lumbar interbody fusion with pedicle screw fixation for degenerative disease of the lumbar spine. All information was collected prospectively and informed consent was obtained from each patient. We excluded 25 patients; nine with a chronic inflammatory disease such as rheumatoid arthritis (RA), and 16 who had undergone previous surgery to the lumbar spine. There were 62 men and 81 women in the remaining 143 patients, with a mean age of 63 years (18 to 80$)$ at the time of surgery. The preoperative diagnosis was degenerative spondylolisthesis in 107 patients, isthmic spondylolisthesis in 25 , lumbar canal stenosis in six and lumbar disc herniation in five. Each patient underwent a single-level posterior lumbar interbody fusion using the Steffee Variable Screw placement (VSP) system (DePuy Spine, Raynam, Massachusetts) and a Brantigen Interbody Fusion (IF) (DePuy Spine) cage packed with bone obtained from the resected lamina. No patient required an additional posterolateral fusion. No bone substitutes or autograft were used. Only autologous blood transfusion was used. Each patient received $2 \mathrm{~g}$ of cefazolin intravenously per day, starting at induction of anaesthesia and continuing for three days. No oral antibiotics were used.

The CRP, WBC and temperature were measured for one or two days before surgery and on days 1, 4, 7 and 14 after. The blood was collected at a fixed time each morning. The CRP was measured using the latex agglutination method (automatic analyser, 7600210S; Hitachi, Tokyo, Japan) and the reagent used was CRP-latex X2 (Roche Diagnostics K.K., Tokyo, Japan). The normal CRP level in our hospital is $<3 \mathrm{mg} / \mathrm{l}$. The WBC was counted by the automatic cell counter (XE2100; Sysmex, Tokyo, Japan) and the normal level was $4500 / \mu / 1$ to $8000 / \mu / 1)$. The patient's 


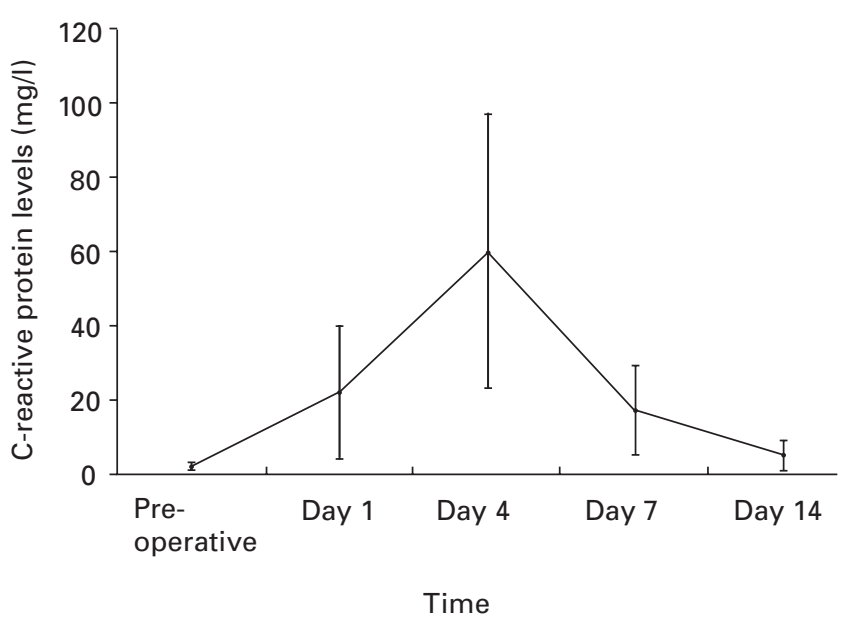

Fig. 1

Graph showing change in C-reactive protein levels. The C-reactive protein decreased after day 4 in all patients. The highest $\mathrm{C}$-reactive protein value on day 4 was $180 \mathrm{mg} / \mathrm{l}$ and on day 7 was $84 \mathrm{mg} / \mathrm{l}$. Bars indicate standard deviation.

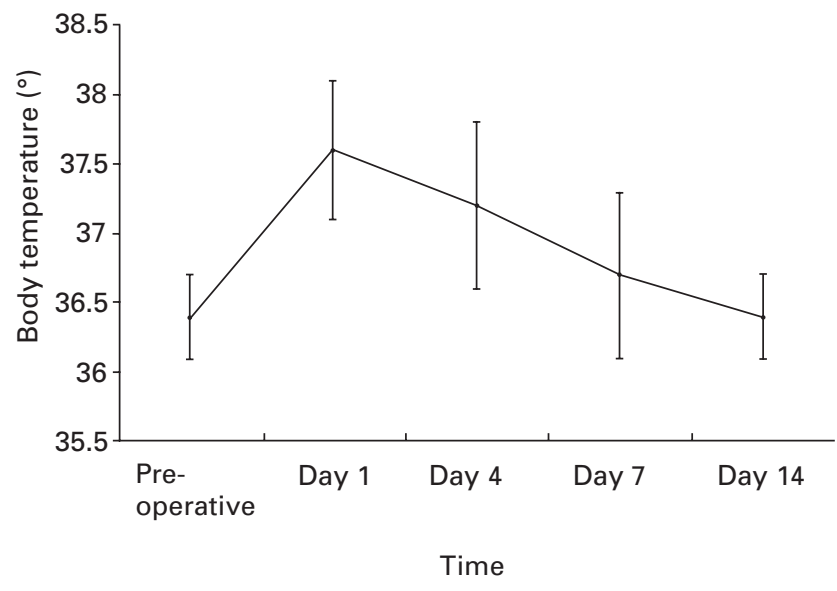

Fig. 3

Graph showing change in body temperature. The highest body temperature was recorded on day 1 in $65 \%$ of the patients. In $25 \%$ a body temperature of more than $37^{\circ} \mathrm{C}$ was recorded on day 7. Bars indicate standard deviation.

temperature was measured with a digital clinical thermometer each morning. The operating time and intra-operative blood loss were also recorded. Patients were followed for one year after their surgery to determine whether any infection had developed.

Statistical analysis was performed using multiple regression analysis with correlation coefficients, and Wilcoxon's signed ranks test with Bonferroni's correction using Stat View (SAS Institute Inc., Cary, North Carolina). The transition of each measurement was analysed statistically and

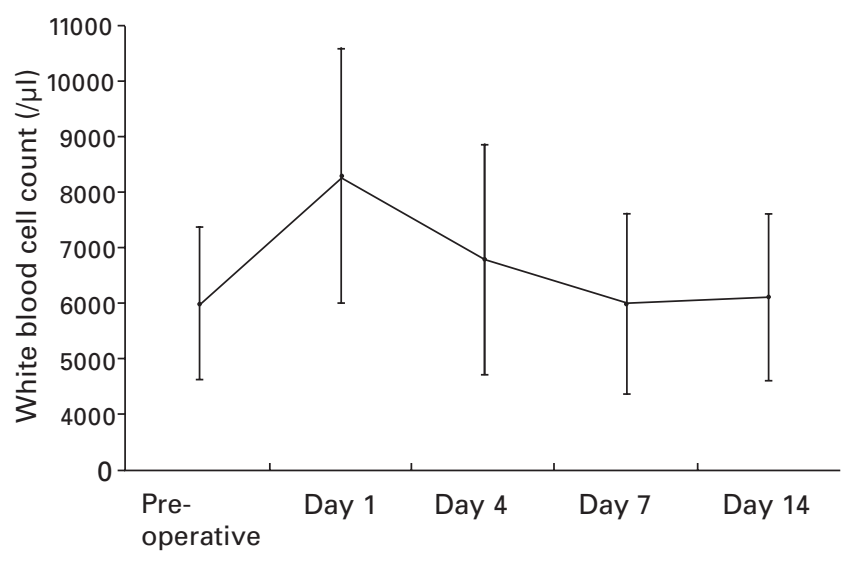

Time

Fig. 2

Graph showing change in white blood cell count. The peak white blood cell count was on day 1 in $87 \%$ of the patients and tended to return to its pre-operative level by day 7. Bars indicate standard deviation. on day 1 , day 1 to day 4 , day 4 to day 7 and day 7 to day 14. A p-value $<0.05$ was considered statistically significant.

\section{Results}

No patient developed an infection within a year of their operation. The mean operating time was 155 mins ( 80 to 240 ) and the mean intra-operative blood loss was $480 \mathrm{ml}$ (50 to 2300). The pre-operative CRP level was within the normal range in all patients. The mean post-operative CRP level rose to a maximum of $60 \mathrm{mg} / \mathrm{l}$ (13 to 180$)$ on day 4, and decreased to $5 \mathrm{mg} / \mathrm{l}$ (1 to 38 ) on day 14 (Fig. 1). The mean WBC was $6000 \mu / 1$ (2700 to 11000$)$ pre-operatively rose to a maximum of $8300 \mu / 1$ (5300 to 15800 ) on day 1 , returned to $6000 \mu / 1$ (3800 to 13300$)$ on day 7 , and was $6100 \mu / 1$ (2300 to 12400$)$ on day 14 (Fig. 2). The mean body temperature was $36.4^{\circ} \mathrm{C}\left(35.5^{\circ} \mathrm{C}\right.$ to $\left.37.1^{\circ} \mathrm{C}\right)$ preoperatively, $37.6^{\circ} \mathrm{C}\left(36.8^{\circ} \mathrm{C}\right.$ to $\left.39.2^{\circ} \mathrm{C}\right)$ on day $1,37.2^{\circ} \mathrm{C}$ $\left(35.8^{\circ} \mathrm{C}\right.$ to $\left.38.8^{\circ} \mathrm{C}\right)$ on day $4,36.7^{\circ} \mathrm{C}\left(35.5^{\circ} \mathrm{C}\right.$ to $\left.38.0^{\circ} \mathrm{C}\right)$ on day 7 and $36.4^{\circ} \mathrm{C}\left(35.4^{\circ} \mathrm{C}\right.$ to $\left.37.4^{\circ} \mathrm{C}\right)$ on day 14 (Fig. 3). There was a statistically significant difference between each mean value of CRP and body temperature. Similarly, there was a significant difference between the WBC counts except between day 7 and day 14. The CRP lay within the normal range $(<3 \mathrm{mg} / \mathrm{l}$ ) on day 14 , in $48 \%$ (69 of 143 ) of patients, between $3 \mathrm{mg} / \mathrm{l}$ and $15 \mathrm{mg} / \mathrm{l}$ in $50 \%$ (72 of 143), and was $>15 \mathrm{mg} / \mathrm{l}$ in $1.4 \%$ ( 2 of 143 ) of the patients. The CRP peaked on day 4 in $94 \%$ of patients (134 of 143) and on day 1 in the rest. In each patient, the CRP on day 7 was lower than that on day 4 , and the CRP on day 14 was lower than that on day 7. The WBC count peaked on day 1 in $87 \%$ of the patients ( 124 of 143 ) and on day 4 in the rest. The highest body temperature was recorded on day 1 in $65 \%$ of the patients (93 of 143), on day 4 in $29 \%$ (41 
of 143), and both on days 1 and 4 in $6 \%$ (9 of 143). There were $25 \%$ (36 patients) whose body temperature was more than $37^{\circ} \mathrm{C}$ on day 7 . There was no statistical correlation between the elevation of the inflammatory markers and age, gender, operating time or intra-operative blood loss. Significant correlation was seen only between the WBC count and the CRP value on each day.

\section{Discussion}

It is often difficult to make an early diagnosis of postoperative spinal infection before clinical symptoms become apparent. ${ }^{3}$ Magnetic resonance imaging can help to diagnose the soft-tissue changes but is expensive to use as a screening tool and may not be available; it may, in any event, fail to show a relevant abnormality because of metal artifact even with titanium implants.

De Winter et $\mathrm{al}^{6}$ have shown that ${ }^{99 \mathrm{~m}} \mathrm{Tc}$ ciprofloxacin planar and tomographic imaging can assist a diagnosis of infection in the post-operative spine, but only after six months. De Winter et $\mathrm{al}^{7}$ also described the use of 18 fluorine fluorodeoxyglucose positron emission tomography in these cases, but noted some false positives, especially in patients with metallic implants.

How, then, may infection be detected early? Although the post-operative changes in the levels of inflammatory markers have been studied after joint replacement, there are few such reports after spinal surgery. ${ }^{8-14}$

Several authors have reported that CRP is the most sensitive inflammatory marker. ${ }^{8,9,11,13-15}$ We did not measure erythrocyte sedimentation rate (ESR) because of its limited value in the detection of infection. ${ }^{8,16}$ The WBC and body temperature vary widely by day and between individuals. In our study, CRP decreased progressively post-operatively between day 4 and day 14 without exception, whereas the WBC increased in 19\% (27 of 143) of the patients and body temperature increased in $8 \%$ (11 of 143) between day 4 and 7 , although they were not infected.

C-reactive protein, an acute-phase protein synthesised by hepatocytes, rises within six hours of bacterial infection. In thoracic and abdominal surgery, CRP has been shown to be more useful than ESR in the early detection of post-operative infection. ${ }^{17}$ Because the rise in CRP depends on the type of surgery, the daily changes in CRP for each procedure should be determined for uncomplicated cases for use as a screening index. Thelander and Larsson $^{13}$ were the first to report changes in the level of CRP after instrumented posterior lumbar interbody fusion. It reached its peak on the third day and decreased to a normal level over five to 14 days in all 17 patients. In our series, the CRP had returned to normal in only $48 \%$ of patients after two weeks. ${ }^{3}$ We think that the difference between the two sets of results arises from differences in the sensitivity of the two methods used to measure the level of CRP. In our study, the CRP was measured using the latex agglutination method, whereas Thelander and Larsson ${ }^{13}$ measured it by fluorescence polarisation immu- noassay. The sensitivity of the latex method is said to be much greater. Given that most authors now use the latex agglutination method for CRP measurement, we feel that our data should be used as a reference. Takahashi et $\mathrm{al}^{14}$ used the same method and found that the post-operative CRP reached its peak on day 2 and remained abnormally elevated even after six weeks. However, their patients had a wide variety of spinal conditions, so the procedures undertaken and instrumentation used varied enormously and resulted in a mean operating time which was much higher than ours (458 vs 155 mins). Although multiple regression analysis revealed no correlation between peak CRP and operating time in their report, the peak CRP levels are generally higher after more extensive or time-consuming surgery as a larger amount of tissue is injured during the larger operations.

In our study, $13 \%$ (19 of 143 ) of patients had a CRP level of more than $100 \mathrm{mg} / \mathrm{l}$ on the fourth post-operative day; the highest recorded was $180 \mathrm{mg} / \mathrm{l}$. Although deep wound infection was suspected in each case, none occurred. We concluded that an elevated CRP does not in itself imply infection, but a later rise should suggest the possibility of infection.

In conclusion, $52 \%$ of the patients who underwent posterior lumbar interbody fusion with posterior instrumentation had an elevated CRP 14 days later, although they were not infected. Age, gender, body temperature, operating time and blood loss did not affect the level of CRP. A rise in CRP between days 4 and 14 after surgery may suggest infection, but we did not identify an infected fusion during the study period.

No benefits in any form have been received or will be received from a commercial party related directly or indirectly to the subject of this article.

\section{References}

1. Rivet DJ, Jeck D, Brennan J, Epstein A, Lauryseen C. Clinical outcomes and complications associated with pedicle screw fixation-augmented lumbar interbody fusion. J Neurosurg Spine 2004;1:261-6.

2. Okuda S, Miyauchi A, Oda T, et al. Surgical complications of posterior lumbar interbody fusion with total facetectomy in 251 patients. J Neurosurg Spine 2006; $1: 304-9$

3. Singh K, Rechtine G, Heller JG. Postoperative spinal infections. In: Herkowitz HN, Garfin ST, Eismont FJ, Bell GR, Balderston RA, eds. The spine. Fifth ed. Vol 2. Elsevier Inc., Philadelphia: Saunders, 2006:1496-510.

4. Pappou IP, Papadopoulos EC, Sama AA, Girardi FP, Cammisa FP. Postoperative infections in interbody fusion for degenerative spinal disease. Clin Orthop 2006;444:120-8

5. Singh K, Samartzis D, Heller JG, An HS, Vaccaro AR. The management of complex soft-tissue defects after spinal instrumentation. J Bone Joint Surg [Br] 2006; 88B: 8-15.

6. De Winter F, Gemmel F, Van Laere K, et al. 99mTc-ciprofloxacin planar and tomographic imaging for the diagnosis of infection in the postoperative spine: experience in 48 patients. Eur J Nucl Med Mol Imaging 2004;31:233-9.

7. De Winter F, Gemmel F, Van De Wiele C, et al. 18-fluorine fluorodeoxyglucose positron emission tomography for the diagnosis of infection in the postoperative spine. Spine 2003;28:1314-19.

8. Aaolto K, Osterman K, Peltola H, Räsänen J. Changes in erythrocyte sedimentation rate and C-reactive protein after total hip arthroplasty. Clin Orthop 1984;184:11820.

9. Larsson S, Thelander U, Friberg S. C-reactive protein (CRP) levels after elective orthopaedic surgery. Clin Orthop 1992;275:237-42. 
10. Niskanen RO, Korkala O, Pammo H. Serum C-reactive protein levels after total hip and knee arthroplasty. J Bone Joint Surg [Br] 1996;78-B:431-3.

11. Shih L-Y, Wu J-J, Yang D-J. Erythrocyte sedimentation rate and C-reactive protein values in patients with total hip arthroplasty. Clin Orthop 1987;225:238-46.

12. White J, Kelly M, Dunsmuir R. C-reactive protein levels after total hip and knee replacement. J Bone Joint Surg [Br] 1998;80-B:909-11.

13. Thelander $\mathbf{U}$, Larsson $\mathbf{S}$. Quantitation of $\mathrm{C}$-reactive protein levels and erythrocyte sedimentation rate after spinal surgery. Spine 1992;17:400-4.
14. Takahashi J, Ebara S, Kamimura M, et al. Early-phase enhanced inflammatory reaction after spinal instrumentation surgery. Spine 2001;26:1698-704.

15. Bottner F, Wegner A, Winklemann W et al. Interleukin - 6 procalcitonin and TNF - $\alpha$ markers of peri-prosthetic infection following total joint replacement. J Bone Joint Surg [Br] 2007;89-B:94-9

16. Carlsson AS. Erythrocyte sedimentation rate in infected and noninfected total hip arthroplasties. Acta Orthop Scand 1978;49:287-90.

17. Mustard RA Jr, Bohnen JM, Haseeb S, Kashina R. C-reactive protein levels predict postoperative septic complications. Arch Surg 1987:122:69-73. 